Tropical Journal of Pharmaceutical Research April 2016; 15 (4): 815-819

ISSN: $1596-5996$ (print); 1596-9827 (electronic)

(C) Pharmacotherapy Group, Faculty of Pharmacy, University of Benin, Benin City, 300001 Nigeria.

All rights reserved.

Available online at http://www.tjpr.org

Original Research Article

http://dx.doi.org/10.4314/tjpr.v15i4.21

\title{
Multi-drug resistant Staphylococcus aureus isolated from emergency ward of an Iranian hospital
}

\author{
Koorosh Ahmadi ${ }^{1}$, Hossein Zakeri $^{2}$, Hamid Zamani Moghadam Doloo ${ }^{2}$, Behrang \\ Rezvani Kakhki ${ }^{2}$, Ali Mohammadshahi ${ }^{3}$, Mostafa Alavi-Moghaddam ${ }^{4}$ and Amir \\ Masoud Hashemian ${ }^{2 *}$ \\ ${ }^{1}$ Department of Emergency Medicine, Alborz University of Medical Sciences, Karaj, Iran, ${ }^{2}$ Department of Emergency \\ Medicine, Mashhad University of Medical Sciences, Mashhad, Iran, ${ }^{3}$ Department of Emergency Medicine, AJA University \\ of Medical Sciences, Tehran, Iran, ${ }^{4}$ Department of Emergency Medicine, Infectious Disease Specialist, Shahid Beheshti \\ University of Medical Sciences, Tehran, Iran
}

${ }^{\star}$ For correspondence: Email: HashemianAM@mums.ac.ir; Tel: +98-9124244517

\begin{abstract}
Purpose: To study the prevalence of resistant strains of S. aureus isolated from surfaces, beds and various equipment of an Iranian hospital emergency ward.

Methods: Two hundred swab samples were collected from the surfaces, beds, trolleys, surgical equipment and diagnostic medical devices in emergency ward. Samples were cultured and those that were S. aureus-positive were confirmed using polymerase chain reaction (PCR). Antimicrobial resistance pattern was analyzed using disk diffusion method.

Results: Nine of 200 samples (4.5\%) collected were positive for S. aureus. Surfaces (8.8\%), beds (5 $\%)$ and trolleys (5\%) were the most commonly contaminated. S. aureus isolates exhibited varying levels of resistance against antibiotics with the following being the highest: tetracycline (88.8\%), penicillin ( $88.8 \%)$ and ampicillin (77.7\%). The prevalence of resistance against methicillin, oxacillin and azithromycin were 44.4, 33.3 and $33.3 \%$, respectively. There was no pattern of resistance against imipenem.

Conclusion: Efficient disinfection of surfaces, beds, trolleys and surgical instruments should be performed periodically to reduce colonization of resistant strains of $S$. aureus in various areas of emergency health care centers.
\end{abstract}

Keywords: Staphylococcus aureus, Nocosomial infection, Antibiotic resistance, Hospital equipment, Emergency ward

Tropical Journal of Pharmaceutical Research is indexed by Science Citation Index (SciSearch), Scopus, International Pharmaceutical Abstract, Chemical Abstracts, Embase, Index Copernicus, EBSCO, African Index Medicus, JournalSeek, Journal Citation Reports/Science Edition, Directory of Open Access Journals (DOAJ), African Journal Online, Bioline International, Open-J-Gate and Pharmacy Abstracts

\section{INTRODUCTION}

Emergency health care centers of hospitals are often full of patients with critical and emergency situations. These patients are mainly the sources of dangerous pathogenic bacteria. Therefore, disinfection of surfaces, beds, equipment and facilities of the emergency health care centers can help to prevent the spread of bacterial strains which are mainly resistant to majority of antibiotics. High numbers of accident cases referred to hospitals and also lack of attention to hygienic principles can result in the occurrence of air-borne infections in hospital environment.

Staphylococcus aureus (S. aureus) has long been considered as a major pathogen of hospital infections all-around the world. It has been 
associated with bacteremia, infective endocarditis and various types of infections including skin and soft tissue, osteoarticular, pleuropulmonary, urinary tract and device-related [1-3]. The ability of $S$. aureus to develop resistance to certain environmental conditions and also wide range of antibiotics and disinfectant agents. Bacteria have been implicated as a cause of long-term survival pathogens in the environment [4].

High capability of $S$. aureus to develop resistance to most antibiotics, has caused problems in the treatment of hospital infections. It has been documented that majority of $S$. aureus strains were resistant to oxacillin, ampicillin, methicillin, penicillin, tetracycline, co trimoxazole, azithromycin, cefexim and clindamycin [5-7]. In recent years prevalence of resistance against several types of antibiotics has increased throughout the world [5-8]. Methicillin-resistant $S$. aureus (MRSA) has caused substantial public health problem worldwide, with significant morbidity, mortality and high cost of health care [9]. There was an estimated 94,360 invasive MRSA infections in the United States in 2005, causing more than 18, 000 deaths per year [10].

Due to inadequate hygienic conditions of Iranian emergency health care centers, the present investigation was carried out in order to determine the prevalence of multi-drug resistant $S$. aureus isolates from the environment and equipment of the centers.

\section{EXPERIMENTAL}

\section{Sample collection}

A total of 200 swab samples were directly collected from various parts and equipment of emergency health care centers including surfaces $(n=45)$, beds $(n=40)$, trolleys $(n=40)$, surgical instruments $(n=45)$ and diagnostic medical devices $(n=30)$. All samples were immediately transferred to the laboratory at $4{ }^{\circ} \mathrm{C}$ in a cooler with ice packs.

\section{Staphylococcus aureus identification}

All samples were directly cultured into $7 \%$ sheep blood agar (Merck, Darmstadt, Germany) and incubated aerobically at $37{ }^{\circ} \mathrm{C}$ for $48 \mathrm{~h}$. After incubation, suspicious colonies were examined by the use of morphologies compatible with Staphylococcus spp. (microscopical morphology, catalase and coagulase production). Studied colonies were cultured on Tryptic Soy Broth (TSB) (Merck, Darmstadt, Germany) and Tryptic
Soy Agar (TSA) (Merck, Darmstadt, Germany). After growth, staphylococci were identified on the basis of colony characteristics, Gram staining, pigment production, hemolytic and the following biochemical reactions: catalase activity, coagulated test (rabbit plasma), Oxidase test, glucose O/F test, resistance to bacitracin (0.04 U), mannitol fermentation on Mannitol Salt Agar (MSA) (Merck, Darmstadt, Germany), urease activity, nitrate reduction, novobiocin resistance, phosphatase, deoxyribonuclease (DNase) test and carbohydrate (xylose, sucrose, trehalose and maltose, fructose, lactose, mannose) fermentation test [11].

\section{Antimicrobial susceptibility test}

Pattern of antimicrobial resistance was studied using the simple disk diffusion technique. The Mueller-Hinton agar (Merck, Germany) medium was used for this purpose. Antibiotic resistance of $S$. aureus strains against 15 commonly used antibiotics in the cases of UTIs was determined using the instruction of Clinical and Laboratory Standards Institute guidelines [12]. Susceptibility of $S$. aureus isolates were tested against ampicillin (10 u/disk), imipenem (30 u/disk), methicillin (30 $\mathrm{gg} / \mathrm{disk})$, tetracycline (30 $\mu \mathrm{g} / \mathrm{disk})$, norfloxacin (30 $\mu \mathrm{g} /$ disk), cotrimoxazole (30 $\mu \mathrm{g} /$ disk), clindamycin (2 $\mu \mathrm{g} /$ disk), penicillin (10 $\mathrm{u} /$ disk), oxacillin (1 $\mu \mathrm{g} /$ disk), azithromycin (15 $\mu \mathrm{g} /$ disk) and cefexime (5 $\mu \mathrm{g} /$ disk) antibiotic agents (Oxoid, UK). The plates containing the discs were allowed to stand for at least $30 \mathrm{~min}$ before incubated at $35^{\circ} \mathrm{C}$ for $24 \mathrm{~h}$. The diameter of the zone of inhibition produced by each antibiotic disc was measured and interpreted using the CLSI zone diameter interpretative standards (CLSI 2012) [12]. S. aureus ATCC 43300 and $K$. pneumoniae ATCC 4352 were used as standard organisms in antimicrobial susceptibility determination.

\section{DNA extraction and PCR confirmation}

Total genomic DNA was extracted from the bacterial colonies using the genomic DNA extraction kit (Fermentas, Germany) according to the manufacture instruction. The DNA concentration was determined by measuring absorbance of the sample at $260 \mathrm{~nm}$ using spectrophotometer [13]. Presence of $S$. aureus in each DNA samples was confirmed using the Daniel et al [14] method. The PCR reaction mix consist of $1 \mathrm{X}$ PCR buffer $(10 \mathrm{mM}$ Tris- $\mathrm{HCl}, \mathrm{pH}$ $8.3,50 \mathrm{mM} \mathrm{KCl}$ and $0.001 \%(\mathrm{w} / \mathrm{v})$ gelatin) with 4 $\mathrm{mM} \mathrm{MgCl} 2,250 \mathrm{mM}$ of each nucleotide (deoxynucleoside triphosphate), $0.5 \mathrm{mM}$ of each primer ( $F$ : 5'-GGAATTCAAAGGAATTGACGGG G GC-3' and R: 5'-CGGGATCCCAGGCCCGG 
GAACGTATTCAC -3') (479 bp size of product for $16 S$ rRNA gene of the $S$. aureus), 4 ng of the molecular beacon and $4 \mathrm{U}$ of Jumpstart Taq DNA polymerase (Fermentas, Germany).

\section{Statistical analysis}

Data were entered into Microsoft Excel spreadsheet (Microsoft Corp, Redmond, WA, USA) for analysis. Using SPSS 16.0 statistical software (SPSS Inc., Chicago, IL, USA), Chisquare test and Fisher's exact two-tailed test analysis were performed and differences were considered significant at $p<0.05$. Distribution of $S$. aureus and antibiotic resistance pattern were statistically analyzed.

\section{RESULTS}

A total of 200 swab samples obtained from various sites of emergency health care centers were analyzed for presence of $S$. aureus. Table 1 shows the distribution of $S$. aureus in various types of swab samples. Of 200 swab samples studied, 9 samples $(4.5 \%)$ were positive for $S$. aureus. Swab samples which was collected from the surfaces of emergency health care centers was the most commonly contaminated $(8.8 \%)$, followed by beds (5\%) and trolleys (5\%). Statistically significant difference was seen for the prevalence of $S$. aureus between the samples collected from surfaces and surgical instruments $(p=0.021)$ and also beds and surgical instruments $(p=0.039)$. There were no positive results for the swabs taken from diagnostic medical devices. The results of culture technique were also confirmed by the PCR method. Figure 1 shows the results of the gel electrophoresis for the identification of 16S rRNA gene of the $S$. aureus strains.

Table 2 shows the antibiotic resistance pattern of the $S$. aureus strains isolated from the swab samples taken from various sites of the emergency health care centers. We found that the $S$. aureus strains were resistant to tetracycline $(88.8 \%)$, penicillin $(88.8 \%)$ and Table 2: Susceptibility of Staphylococcus aureus commonly used antibiotics ampicillin $(77.7 \%)$. The prevalence of resistance against methicillin, oxacillin and azithromycin were $44.4,33.3$ and $33.3 \%$, respectively.

However, the isolates were susceptible to imipenem. S. aureus strains of surgical instruments and trolleys had the highest levels of resistance. Statistically significant differences were seen between the resistance against tetracycline and oxacillin $(p=0.019)$, tetracycline

Table 1: Distribution of Staphylococcus aureus from various types of swab samples

\begin{tabular}{lcc}
\hline Sample & $\begin{array}{c}\text { No. of } \\
\text { samples } \\
\text { collected }\end{array}$ & $\begin{array}{c}\text { Positive } \\
\text { strains } \\
(\%)\end{array}$ \\
\hline Surfaces & 45 & $4(8.8)$ \\
Beds & 40 & $2(5)$ \\
Trolleys & 40 & $2(5)$ \\
$\begin{array}{l}\text { Surgical instruments } \\
\begin{array}{l}\text { Diagnostic medical } \\
\text { devices }\end{array}\end{array}$ & 45 & $1(2.2)$ \\
\begin{tabular}{l} 
Total \\
\hline
\end{tabular} & 30 & - \\
\hline
\end{tabular}

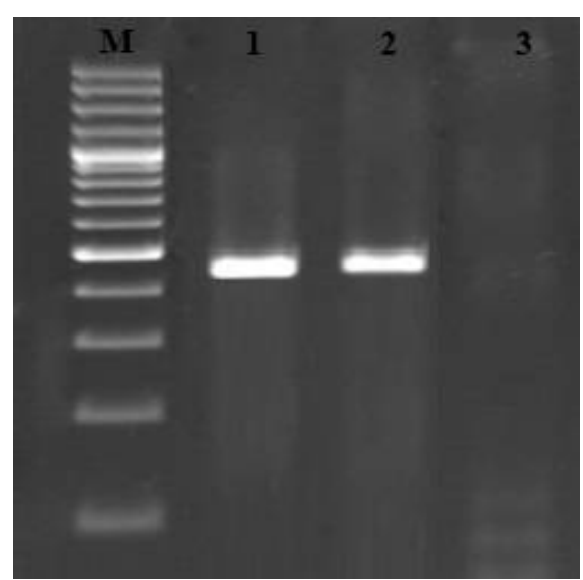

Figure 1: Gel electrophoresis for the identification of $16 S$ rRNA gene of the $S$. aureus strains. M: $100 \mathrm{bp}$ DNA ladder (Fermentas, Germany), Line 1: Positive samples for $16 S$ rRNA gene of the $S$. aureus (479 bp), Line 2: Positive control (S. aureus ATCC 43300), Line 3: Negative control (Distilled water, Merck, Germany). strains of various types of swab samples against

\begin{tabular}{|c|c|c|c|c|c|c|c|c|c|c|c|}
\hline \multirow{2}{*}{$\begin{array}{c}\text { Source of } \\
\text { sample (no. } \\
\text { positive) }\end{array}$} & \multicolumn{11}{|c|}{ Pattern of antibiotic resistance (\%) } \\
\hline & Amp & Imip & Tetra & Meth & Norfl & Cotrimox & Clinda & Pen & Oxa & Azithro & Cefex \\
\hline Surfaces (4) & $3(75)$ & - & $4(100)$ & $3(75)$ & $2(50)$ & $2(50)$ & $2(50)$ & $4(100)$ & $2(50)$ & $2(50)$ & $3(75)$ \\
\hline Beds (2) & $2(100)$ & - & $2(100)$ & $1(50)$ & $1(50)$ & $1(50)$ & $1(50)$ & $2(100)$ & $1(50)$ & $1(50)$ & $1(50)$ \\
\hline Trolleys (2) & $1(100)$ & - & $1(100)$ & - & - & - & - & $1(100)$ & - & - & - \\
\hline $\begin{array}{c}\text { Surgical } \\
\text { instruments } \\
(1)\end{array}$ & $1(100)$ & - & $1(100)$ & - & - & - & - & $1(100)$ & - & - & - \\
\hline Total (9) & $7(77.7)$ & - & $8(88.8)$ & $4(44.4)$ & $3(33.3)$ & $3(33.3)$ & $3(33.3)$ & $8(88.8)$ & $3(33.3)$ & $3(33.3)$ & $4(44.4)$ \\
\hline
\end{tabular}


and methicillin ( $p=0.028)$, penicillin and clindamycin $(p=0.023)$ and penicillin and methicillin $(p=0.030)$.

\section{DISCUSSION}

The results of the present investigation revealed the low incidence $(4.5 \%)$ of resistant strains of $S$. aureus in various sites and equipment of the emergency health care centers of Iranian hospitals. Despite the low incidence of $S$. aureus, the public health implications cannot be downplayed in emergency care centers. One possible explanation for presence of $S$. aureus could be that the emergency health care centers is the fact that the environment of the emergency health care centers was heavily contaminated. It may also be indicative of improper and inadequate disinfection of surfaces and equipment. Reports showed that $S$. aureus survived adverse situation like high levels of acidity, dryness and salty conditions [15-17], and hospital environment [18-20].

In a study by Alebachew et al [21], the $S$. aureus strains of human clinical infections were sensitive to clindamycin, vancomycin, erythromycin, and kanamycin but highly resistant to penicillin. They showed that all isolates were multi-drug resistant, and one isolate was resistant to all the tested drugs. In a research in Iran [22], $60 \%$ of all $S$. aureus isolates of hospital infections were resistant to methicillin. Ekrami et al [22] showed that the highest resistance was to ciprofloxacin (81.2 \%) while Momtaz and Hafezi [23] found that $S$. aureus isolates from hospital infections were resistant to azithromycin (62.12 \%), tetracycline $(57.57 \%)$ and erythromycin (54.54 $\%)$.

S. aureus strains obtained in this study were fully susceptible to imipenem, moderately susceptible to norfloxacin, cotrimoxazole, clindamycin, oxacillin and azithromycin antibiotics. Similar results have been reported previously [21-23]. Methicillin was one of the first lines of drugs for the chemical management of $S$. aureus infections. The resistance against this antibiotic in this study was $44.4 \%$. Important role of methicillin resistant $S$. aureus (MRSA) as causative agent of human clinical infections has been reported previously [21-25]. The observed antibiotic resistance in our study maybe due to the moderately high prescription of methicillin in Iranian health center and hospitals. In addition, this finding may be reflective of the possible failure of internal disinfection process in the hospital's environment.

\section{CONCLUSION}

The results of the present investigation indicate that $S$. aureus might be an important causative agent of nocosomial infections in emergency centers of hospitals. Accurate and continuous surveillance of antibiotic resistance patterns among $S$. aureus strains should be considered in emergency health care centers. Prescription of imipenem for the treatment of cases of $S$. aureus is recommended. Effective disinfection of surfaces, beds, trolleys and surgical instruments by hospital infection control unit should be performed periodically to reduce colonization of $S$. aureus in various areas of hospital emergency wards.

\section{ACKNOWLEDGEMENT}

The authors would like to thank Dr F Safarpoor Dehkordi, Department of Food Hygiene and Quality Control, University of Tehran, for technical support.

\section{REFERENCES}

1. Megged O. Staphylococcus aureus urinary tract infections in children are associated with urinary tract abnormalities and vesico-ureteral reflux. Pediatr Nephrol 2014; 29(2): 269-272.

2. Shrestha B, Pokhrel B, Mohapatra T. Study of nosocomial isolates of Staphylococcus aureus with special reference to methicillin resistant $S$. aureus in a tertiary care hospital in Nepal. Nepal Med Coll J 2009; 11(2): 123-126.

3. Yahaghi E, Imani Fooladi AA, Amin M, Mirnejad $R$, Nezamzade R, Amani J. Detection of Class I Integrons in Staphylococcus aureus isolated from Clinical Samples. Iran Red Crescent Med J 2014; 16(11): e16234.

4. Holland TL, Arnold C, Fowler VG Jr. Clinical management of Staphylococcus aureus bacteremia: a review. JAMA 2014; 312(13): 1330-1341.

5. Campoccia D, Montanaro L, Baldassarri $L$, An $Y H$, Arciola CR. Antibiotic resistance in Staphylococcus aureus and Staphylococcus epidermidis clinical isolates from implant orthopedic infections. Int J Artif Organs 2005; 28(11): 1186-1191.

6. Onanuga A, Awhowho GO. Antimicrobial resistance of Staphylococcus aureus strains from patients with urinary tract infections in Yenagoa, Nigeria. $J$ Pharm Bioallied Sci 2012; 4(3): 226-230.

7. Tokajian S, Haddad H, Andraos R, Hashwa F, and Araj G. Toxins and Antibiotic Resistance in Staphylococcus 
aureus Isolated from a Major Hospital in Lebanon. ISRN Microbiol 2011; 2011: 1-9. doi:10.5402/2011/812049.

8. Goud R, Gupta S, Neogi U, Agarwal D, Naidu K, Chalannavar $R$, Subhaschandra $G$. Community prevalence of methicillin and vancomycin resistant Staphylococcus aureus in and around Bangalore, southern India. Rev Soc Bras Med Trop 2011; 44(3): 309-312.

9. Goetghebeur $M$, Landry PA, Han D, Vicente $C$. Methicillin-resistant Staphylococcus aureus: $A$ public health issue with economic consequences. Can J Infect Dis Med Microbiol 2007; 18(1): 27-34.

10. Klevens RM, Morrison MA, Nadle J, Petit S, Gershman K, Ray S, Harrison LH, Lynfield R, Dumyati G, Townes JM. Invasive methicillin-resistant Staphylococcus aureus infections in the United States. JAMA 2007; 298(15): 1763-1771.

11. Zmantar T, Chaieb K, Ben Abdallah F, Ben Kahla-Nakbi A, Ben Hassen A, Mahdouani K, Bakhrouf A. Multiplex $P C R$ detection of the antibiotic resistance genes in Staphylococcus aureus strains isolated from auricular infections. Folia Microbiol (Praha) 2008; 53(4): 357-362.

12. Clinical and Laboratory Standards Institute (CLSI). Performance standards for antimicrobial susceptibility testing; twenty-second informational supplement. M100S21. Wayne Pa: CLSI; 2012.

13. Sambrok, J.A. Molecular Cloning: A Laboratory Manual. 3rd ed. New York; Cold Spring Harbor Laboratory Press; 2001.p. 2100.

14. Daniel JG, James RU, Cynthia AG, David HP. Multiplex $P C R$ for identification of methicillin-resistant staphylococci in the clinical laboratory. J Clin Microbiol 1994; 32(7): 1768-1772.

15. Neely AN, Maley MP. Survival of Enterococci and Staphylococci on Hospital Fabrics and Plastic. J Clin Microbiol 2000; 38(2): 724-726.

16. Huang R, Mehta S, Weed D, Price CS. Methicillinresistant Staphylococcus aureus survival on hospital fomites. Infect Control Hosp Epidemiol 2006; 27(11): 1267-9.
17. Desai R, Pannaraj PS, Agopian J, Sugar CA, Liu GY, Miller LG. Survival and transmission of communityassociated methicillin-resistant Staphylococcus aureus from fomites. Am J Infect Control 2011; 39(3): 219-225.

18. Neely AN, Maley MP: Survival of enterococci and staphylococci on hospital fabric and plastic. J Clin Microbiol 2000; 38(2): 724-726.

19. Wagenvoort JH, Sluijsman W, Penders RJ. Better environmental survival of outbreak vs. sporadic MRSA isolates. J Hosp Infect 2000; 45(3): 231-234.

20. Kramer A, Schwebke I, Kampf G. How long do nosocomial pathogens persist on inanimate surfaces? A systematic review. BMC Infect Dis 2006; 16(6): 130-138.

21. Alebachew $T$, Yismaw $G$, Derabe $A$, Sisay $Z$. Staphylococcus aureus burn wound infection among patients attending yekatit 12 hospital burn unit, addis ababa, ethiopia. Ethiop J Health Sci 2012; 22(3): 209213.

22. Ekrami A, Samarbafzadeh A, Alavi M, Kalantar E, Hamzeloi F. Prevalence of methicillin resistant Staphylococcus species isolated from burn patients in a burn center, Ahvaz, Iran. Jundishapur J Microbiol 2010; 3(2): 84-91.

23. Momtaz H, Hafezi L. Meticillin-resistant Staphylococcus aureus isolated from Iranian hospitals: virulence factors and antibiotic resistance properties. Bosn J Basic Med Sci 2014; 14(4): 219-226.

24. Mehndiratta PL, Bhalla $P$, Ahmed A, Sharma YD. Molecular typing of methicillin-resistant Staphylococcus aureus strains by PCR-RFLP of SPA gene: a reference laboratory perspective. Indian J Med Microbiol 2009; 27(2): 116-122.

25. Havaei SA, Azimian A, Fazeli H, Naderi M, Ghazvini K, Samiee SM, Masoumi Z, Akbari M. Genetic Characterization of Methicillin Resistant and Sensitive, Vancomycin Intermediate Staphylococcus aureus Strains Isolated from Different Iranian Hospitals. ISRN Microbiol 2012; 2012: $215275 . \quad$ doi: $10.5402 / 2012 / 215275$ 